\title{
Serum neutrophil gelatinase-associated lipocalin in obese adolescents
}

\author{
Wafaa A. Kandeel', Heba A. Elmalt², Ola M. Abdel Samie ${ }^{3}$, Hoda A. Megahed², Gehan A. Hegazy 2,4, \\ Elham M. Y. El abd ${ }^{5}$, Naglaa Abdel Moneam ${ }^{6}$, Mahmoud M. Masoud ${ }^{2}$ and Mahmoud A. Abdel-Monem ${ }^{2 *}$ (D
}

\begin{abstract}
Background: Nonalcoholic fatty liver disease (NAFLD) is an emerging clinical problem among obese adolescents.

Methods: This study was conducted on 40 obese adolescents, previously diagnosed by ultrasonography to determine liver status and confirmed to have NAFLD, and 40 non-obese healthy controls matching in age and sex. Anthropometric measurements were taken and the Homeostatic Model Assessment-Insulin Resistance (HOMA-IR) test was performed. Levels of C-reactive protein (CRP) and neutrophil gelatinase-associated lipocalin (NGAL) were measured, and the biochemical parameters like blood glucose, insulin, lipid profile, and liver enzymes (ALT and AST) were also measured.
\end{abstract}

Results: Anthropometric measurements were significantly higher in the obese group than in the control group $(P<0.05)$. Obese adolescents had significantly higher values of serum insulin, HOMA-IR, CRP, ALT, triglycerides, total cholesterol $(P<0.05)$, and NGAL $(P<0.01)$ and a lower HDL-C value than the control group. Also, we found a highly significant correlation between the CRP, insulin, and NGAL levels where $P<0.01$.

Conclusion: NGAL can be used as a biomarker for predicting incidence of NAFLD in obese adolescents.

Trial registration: NRC17006. Registered: 19 January 2017

Keywords: NGAL, NAFLD, Obesity, CRP, Adolescents

\section{Background}

Obesity is a major worldwide health problem and is strongly associated with a number of diseases. There is an increasing evidence that obesity is causally linked to a chronic low-grade inflammatory state as shown by the high levels of inflammatory markers (Polyzos et al. 2017; Wu et al. 2016).

Obesity is frequently associated with insulin resistance which is regarded as a critical factor that contributes to the development of nonalcoholic fatty liver disease (NAFLD) (Neuschwander-Tetri 2017). neutrophil gelatinase-associated lipocalin (NGAL) is secreted by adipocytes and immune cells such as neutrophils and macrophages and was initially described to play a role in innate immunity, perhaps by sequestrating iron (Bulluck et al. 2017). Since NGAL is abundantly

\footnotetext{
* Correspondence: mahmoud199018@gmail.com

${ }^{2}$ Department of Medical Biochemistry, National Research Centre, Cairo 12622, Egypt

Full list of author information is available at the end of the article
}

expressed in adipose tissue and the liver, we suggest that it might be useful as a noninvasive biomarker of NAFLD and in evaluating the outcomes of various clinical interventions in such obesity-related metabolic disease. The aim of our study is to determine the NGAL role in the pathogenesis of NAFLD and to assess its relationship with CRP and insulin resistance among adolescent obese Egyptians.

\section{Methods}

The study group included 40 obese adolescents (BMI > 90th percentile) recruited from an ultrasonography clinic in Al-Zahraa Hospital, Cairo, Egypt. They were 15 males and 25 females, and their ages ranged from 12 to 17 years. Obese participants were previously examined by ultrasonography to detect liver status and confirmed to have NAFLD. The control group comprised 40 non-obese adolescents who were age- and sex-matched with the study group. 


\section{Biochemical analysis}

Morning 5-ml venous blood samples were withdrawn after a 12-h overnight fasting into plane tubes and were left to clot; a small portion of blood was separated in sodium fluoride-coated tubes for glucose level determination. The serum was separated by centrifugation for $10 \mathrm{~min}$ at $5000 \mathrm{rpm}$ and was stored at $-20{ }^{\circ} \mathrm{C}$ until assayed.

Triglyceride (TG), total cholesterol (TC), and highdensity lipoprotein cholesterol (HDL-C) levels were assayed by enzymatic colorimetric methods according to Wahlefeld (1974), Allain et al. (1974), and Warnick et al. (1982) respectively using kits purchased from Spinreact, Girona, Spain. Low-density lipoprotein cholesterol (LDL-C) was calculated using the Friedewald equation $[\mathrm{LDL}-\mathrm{C}=$ total cholesterol - HDL-C - (triglyceride/5)] when the triglyceride concentrations did not exceed $4.8 \mathrm{mmol} / \mathrm{L}$ (Friedewald et al. 1972).

Plasma glucose level was determined by the glucose oxidase method (Barham and Trinder 1972) using a kit purchased from Spinreact, Girona, Spain, and serum insulin was measured by using the quantitative enzymelinked immunosorbent assay (ELISA) using a commercial kit provided by DIA source, Belgium (Turkington et al. 1982).

The Homeostatic Model Assessment-Insulin Resistance (HOMA-IR) method was used for the calculation of insulin resistance. This method has been validated as a reliable measure of insulin resistance in vivo in humans (Michael 2008).

HOMA-IR

$=\frac{\text { Fasting serum insulin }(\mu \mathrm{IU} / \mathrm{ml}) \times \text { fasting plasma glucose }(\mathrm{mmol} / \mathrm{L})}{22.5}$

Serum CRP was measured using the ELISA kit provided by Immunospec, CA, USA (Ridker et al. 1998).

Serum ALT and AST activities were measured by a colorimetric procedure using a kit provided by Linear Chemicals S.L., Barcelona, Spain (Bergmeyer et al. 1985).

Serum NGAL levels were measured using the ELISA kit provided by Bio-Rad, Hercules, CA, USA (Mitsnefes et al. 2007).

\section{Anthropometric parameters}

According to the recommendations of the International Biological Program (Hiernaux and Tanner 1969), anthropometric measurements including height, weight, waist circumferences, and hip circumferences were measured by well-trained anthropologists. Body weight was determined to the nearest $0.01 \mathrm{~kg}$ using a Seca scale balance, Hamburg, Germany, with the subject wearing minimal clothing and no shoes. The body height was measured to the nearest $0.1 \mathrm{~cm}$ in a standing position using a Holtain portable anthropometer with fixed stadiometers. Circumferences were obtained with a flexible non-stretchable measuring tape. The waist circumference (WC) was measured at the midpoint between the lower rib margin and the iliac crest with the subject standing at the end of normal expiration. The hip circumference $(\mathrm{HC})$ was measured at the level of the greater trochanters with the subject wearing minimum clothing. The mean of the two readings was taken in for calculating the waist-to-hip ratio (WHR).

The body mass index (BMI) was calculated by dividing the weight $(\mathrm{kg})$ by the squared value of height in meters. Obese subjects are defined as having a BMI above the 95th percentile for age and sex based on the established percentile curves for Egyptian children and adolescents (Ghalli et al. 2008). Statistical analysis was performed using independent-sample $T$ test for comparison between means and bivariate Pearson test for correlations by SPSS v.16, SPSS Inc. Chicago, USA.

\section{Results}

Sex and age of study subjects are presented in Table 1 and their biochemical parameters are presented in Table 2 and Figs. 1, 2, and 3. Statistics show that the obese group has significantly higher values of serum insulin, HOMA-IR, CRP, ALT, triglycerides, total cholesterol $(P<0.05)$, and NGAL $(P<0.01)$ and lower HDL value than the control group. Also, a highly significant $(P<0.01)$ positive correlation between serum NGAL and CRP $(r=0.88)$ (Fig. 4), CRP and insulin ( $r=0.84)$ (Fig. 5), and NGAL and insulin $(r=0.84)$ (Fig. 6) levels were found.

\section{Anthropometric data}

Table 3 shows comparison of the anthropometric parameters between the control and the obese groups. Statistics show that obese subjects have significantly higher anthropometric measurements than control subjects where $P<0.05$.

Table 1 Sex and age distribution in control and obese groups

\begin{tabular}{lllllll}
\hline & Control & Mean age (years) & $P$ & Obese & Mean age (years) & $P$ \\
\hline Male & $13(32.5 \%)$ & 14.23 & 0.42 & $15(37.5 \%)$ & 14.73 & 0.42 \\
Female & $27(67.5 \%)$ & 14.07 & 0.32 & $25(62.5 \%)$ & 14.6 & 0.29 \\
Total & $40(100 \%)$ & & & $40(100 \%)$ & & \\
\hline
\end{tabular}

(\%) : percent from total subjects, $P$ : SE value 
Table 2 Comparison of laboratory data between control and obese groups

\begin{tabular}{lll}
\hline Parameter & Control & Obese \\
\hline Glucose $(\mathrm{mg} / \mathrm{dl})$ & $90.53 \pm 6.18$ & $95.30 \pm 8.23$ \\
Insulin $(\mu \mathrm{lU} / \mathrm{ml})$ & $5.01 \pm 0.20$ & $11.37 \pm 0.89^{\mathrm{a}}$ \\
HOMA-IR & $0.89 \pm 0.021$ & $4.973 \pm 0.29^{\mathrm{a}}$ \\
AST(U/L) & $24.62 \pm 2.12$ & $25.19 \pm 3.22$ \\
ALT(U/L) & $14.06 \pm 0.84$ & $22.23 \pm 1.51^{\mathrm{a}}$ \\
HDL-cholesterol $(\mathrm{mg} / \mathrm{dl})$ & $49.00 \pm 4.35$ & $46.75 \pm 5.41$ \\
Triglycerides $(\mathrm{mg} / \mathrm{dl})$ & $80.35 \pm 1.63$ & $123.49 \pm 3.79^{\mathrm{a}}$ \\
Total cholesterol $(\mathrm{mg} / \mathrm{dl})$ & $160.13 \pm 8.82$ & $174.66 \pm 11.93^{\mathrm{a}}$ \\
LDL-cholesterol $(\mathrm{mg} / \mathrm{dl})$ & $98.56 \pm 5.74$ & $103.37 \pm 4.65$ \\
C-reactive protein $(\mathrm{ng} / \mathrm{ml})$ & $1320 \pm 29.2$ & $3319 \pm 84.9^{\mathrm{a}}$ \\
NGAL $(\mathrm{ng} / \mathrm{ml})$ & $74.02 \pm 4.78$ & $324.98 \pm 12.3^{\mathrm{b}}$
\end{tabular}

All data are presented as mean $\pm \mathrm{SE}$

${ }^{\text {a }}$ Significant versus control group at $P<0.05$

${ }^{\mathrm{b}}$ Significant versus control group at $P<0.01$

\section{Discussion}

Obesity is almost always associated with a low-grade chronic inflammation due to proinflammatoy cytokine release (Georgio et al. 2013). This inflammation truly represents the critical "link" between obesity and insulin resistance (IR). In turn, IR is the main backbone player in NAFLD pathogenesis. Researches have reported that $76 \%$ of obese adolescents have NAFLD (Georgio et al. 2013; Seung-Hoi 2013; Basaranoglu et al. 2015).

In this study, inflammation was displayed through the significant elevation of the CRP level in the obese group compared to the control group. That striking elevation might not only be due to obesity but also due to NAFLD, where NAFLD could progress from simple steatosis up to steatohepatitis (NASH). Accordingly, there is the additional liver cell inflammation besides that of the adipose tissue cells. Similarly, other studies reported a marked rise of the CRP levels in their obese adolescents compared to the non-obese ones (Esser et al. 2014; Lichtenauer et al. 2015).

Concerning the critical issue of IR, the studied obese adolescents exhibited higher blood glucose levels and significantly higher triglycerides and cholesterol levels compared to their control peers. Consequently, their blood insulin levels were also much higher and their "IR states" were so profound as proved by the HOMA-IR test. In accordance with these findings, many researchers emphasized the presence of IR states in their obese subjects (Lichtenauer et al. 2015; Puspitadewi et al. 2013; Chandrasekhar et al. 2014).

At this point, it is worth noting that our work revealed a significant positive correlation between the CRP and the insulin levels in the obese group $(P=0.001)$. Some studies were matching with this finding and found significant positive correlations between the CRP and the increased risk of type 2 diabetes in their obese subjects (Esser et al. 2014; Wang 2013). Our obese subjects were found to be suffering from NAFLD depending on abdominal ultrasonography examination. This was an expected finding due to several reasons that were confirmed by our investigations and is in agreement with El-Koofy et al. (2012), Seung-Hoi (2013), Georgio et al. (2013), and Huang and Yang (2013).

It was reported that NAFLD incidence increases in the obese and the extremely obese patients (up to 65 and $85 \%$ respectively) whose $\mathrm{BMI}$ is $30-39.9 \mathrm{~kg} / \mathrm{m}^{2}$ respectively (Basaranoglu et al. 2015). In addition Schwimmer et al. (2014) found out that their NAFLD subjects displayed evidences of inflammation and oxidative stress

\section{CRP(ng/ml)}

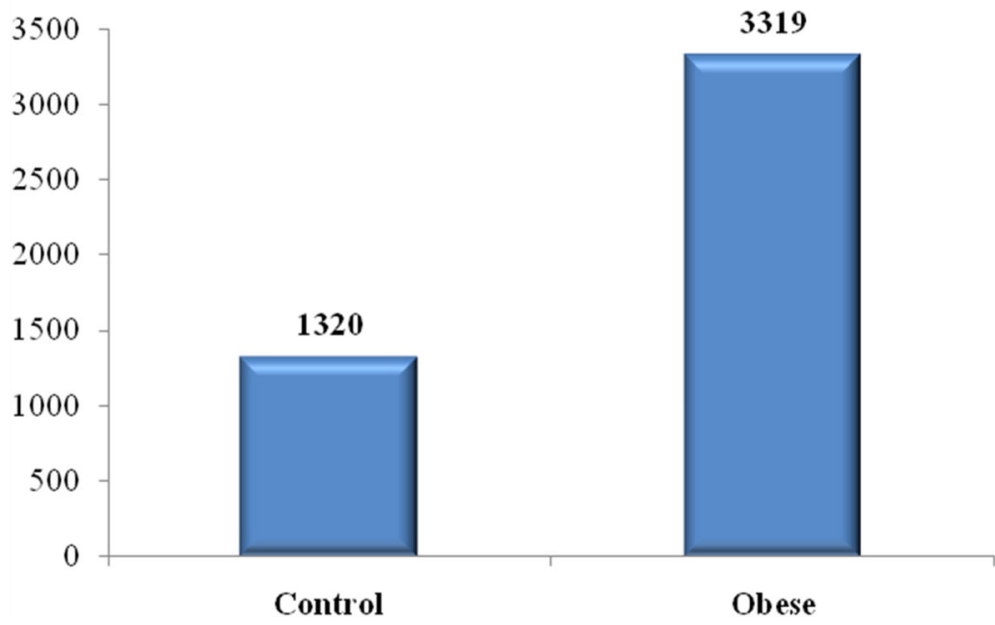

Fig. 1 Comparison of CRP levels between control and obese groups 


\section{$\operatorname{Insulin}(\mu \mathrm{IU} / \mathbf{m I})$}

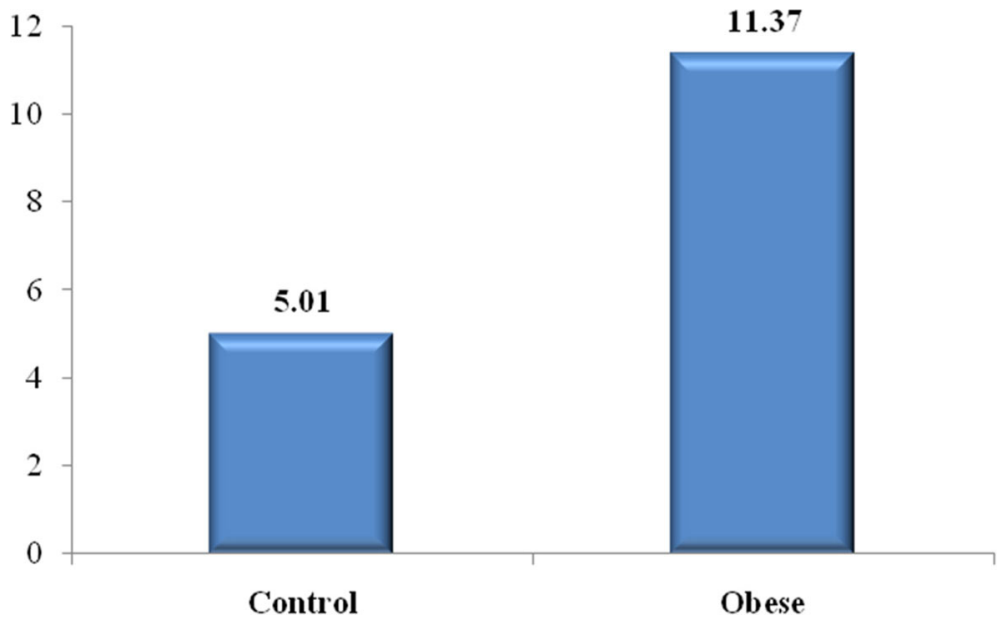

Fig. 2 Comparison of insulin levels between control and obese groups

(OS). This study showed that O.S. is well known to be a driver towards IR. This finding was reported by other work studies.

NAFLD by definition is the excessive accumulation of triglycerides in the liver without alcohol intake (Seung-Hoi 2013), and in our study, obese subjects did have highly significant levels of serum triglycerides and cholesterol.

Our obese group adolescents suffered from visceral adiposity (also called central or abdominal adiposity). This was elicited through their WC, HC, and WHR. All measurements were significantly much higher than those of their control mates. In accordance with us, many researchers have emphasized that the visceral adiposity is much more crucial than mere subcutaneous adiposity concerning the risk of NAFLD occurrence (Fishbein et al. 2006; Fan and Farrell 2008). This may be due to the finding that the visceral adipose tissue plays a pivotal role in NAFLD pathogenesis because it participates in the production of most of the adipokines that are involved in causing inflammation and IR (Georgio et al. 2013).

Matching with our findings and verifying the former explanations, Suarez-Alvarez et al. (2013) and Nappo et al. (2013) found out a significant positive correlation between the high CRP level (inflammation) and the increased waist-to-hip ratio. Several studies emphasized significant positive correlations between IR and waist circumference and BMI (Chandrasekhar et al. 2014; Gobato et al. 2014).

Moreover, in our work, the AST and the ALT enzymes were higher in the obese NAFLD group more than the control group with special referral to the ALT enzyme because it was significantly higher. The "liver fat infiltration" explains that increase in both liver enzymes but as the ALT was reported by some studies to be more sensitive, so its rise was a significant one. Actually, the ALT enzyme is not commonly found outside the liver; accordingly, its high levels mostly accompany the increased liver fat fraction. Many researches confirmed that there was a significant positive correlation between ALT level and liver size in children (Rodriguez et al. 2010; Lenzi et al. 2015).

In our study, the NGAL serum levels were significantly higher in the obese group subjects more than their control peers $(P<0.01)$. In addition, there were highly significant positive correlations between NGAL and the insulin level and also between NGAL and the CRP level. $(P=0.001)$. All that was very much expected because in obesity there is a low-grade chronic inflammation and NGAL is an acute-phase protein, like CRP, and an independent predictor of inflammation (Martins et al. 2014; Zaki et al. 2015).

Actually, many research studies declared NGAL to be an inflammatory marker closely related not only to obesity but also to its metabolic complications of which "IR" is an alarming issue (Wang et al. 2007; Shieh et al. 2014). Concerning the positive correlation between NGAL and insulin resistance (IR), it is worth noting to mention that lipopolysaccharides induce the expression of NGAL in the liver (Martins et al. 2014; Zaki et al. 2015). In obesity, there are high levels of lipopolysaccharides which not only act as inflammatory stimuli but are also one of the reasons why IR occurs. Accordingly, we can consider that lipopolysaccharides are one single common factor or explanation between NGAL high levels and IR state elevation. Another explanation is that NGAL antagonizes the effects of TNF- $\alpha$ in adipocytes and macrophages where TNF- $\alpha$ is well known to promote IR (Martins et al. 2014; Shieh et al. 2014; Dimitrova et al. 2014). 


\section{NGAL (ng/ml)}

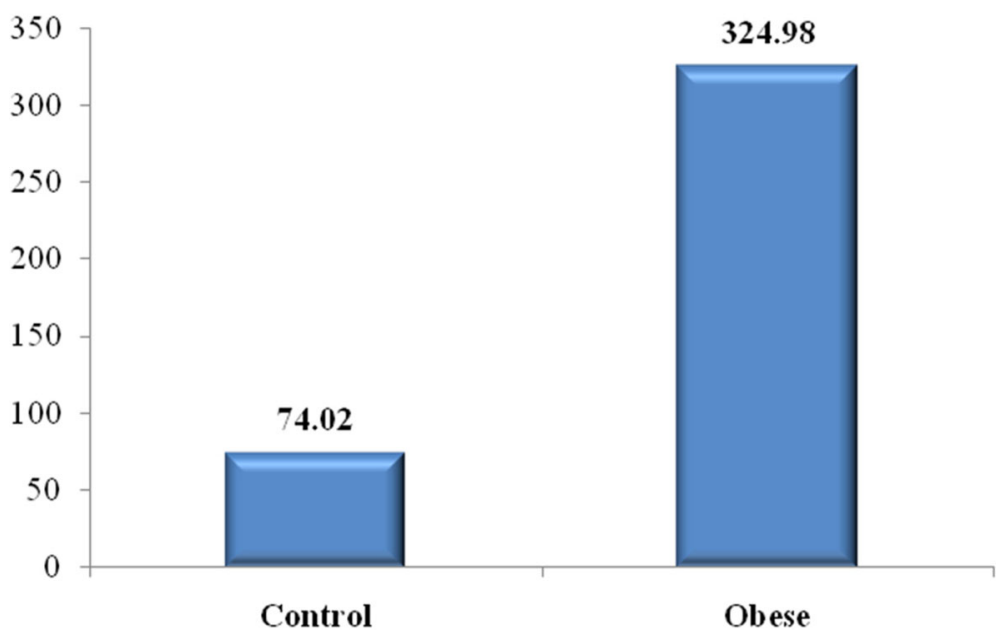

Fig. 3 Comparison of NGAL levels between control and obese groups

In accordance with our results, two studies found out that NGAL expression is increased by agents which promote IR, and this emphasizes its role in obesity IR (Yan et al. 2007; Fried and Greenberg 2012).

Still matching with our findings, Wang et al. (2007) reported that in human beings, NGAL levels correlated positively with IR, hypertriglyceridemia, and BMI. It correlated negatively with HDL-C. However, and contrary to our results, some researchers did not find any relationship between serum NGAL and the anthropometric or the metabolic parameters $(P>0.05)$. Thus, they do not suggest routine NGAL measurements in obese subjects (Akelma et al. 2012).

Liver neutrophil activation is a "double-edged sword" (Xu et al. 2014). Normally, neutrophils (and other cell subsets) have a particular pivotal role in the liver innate

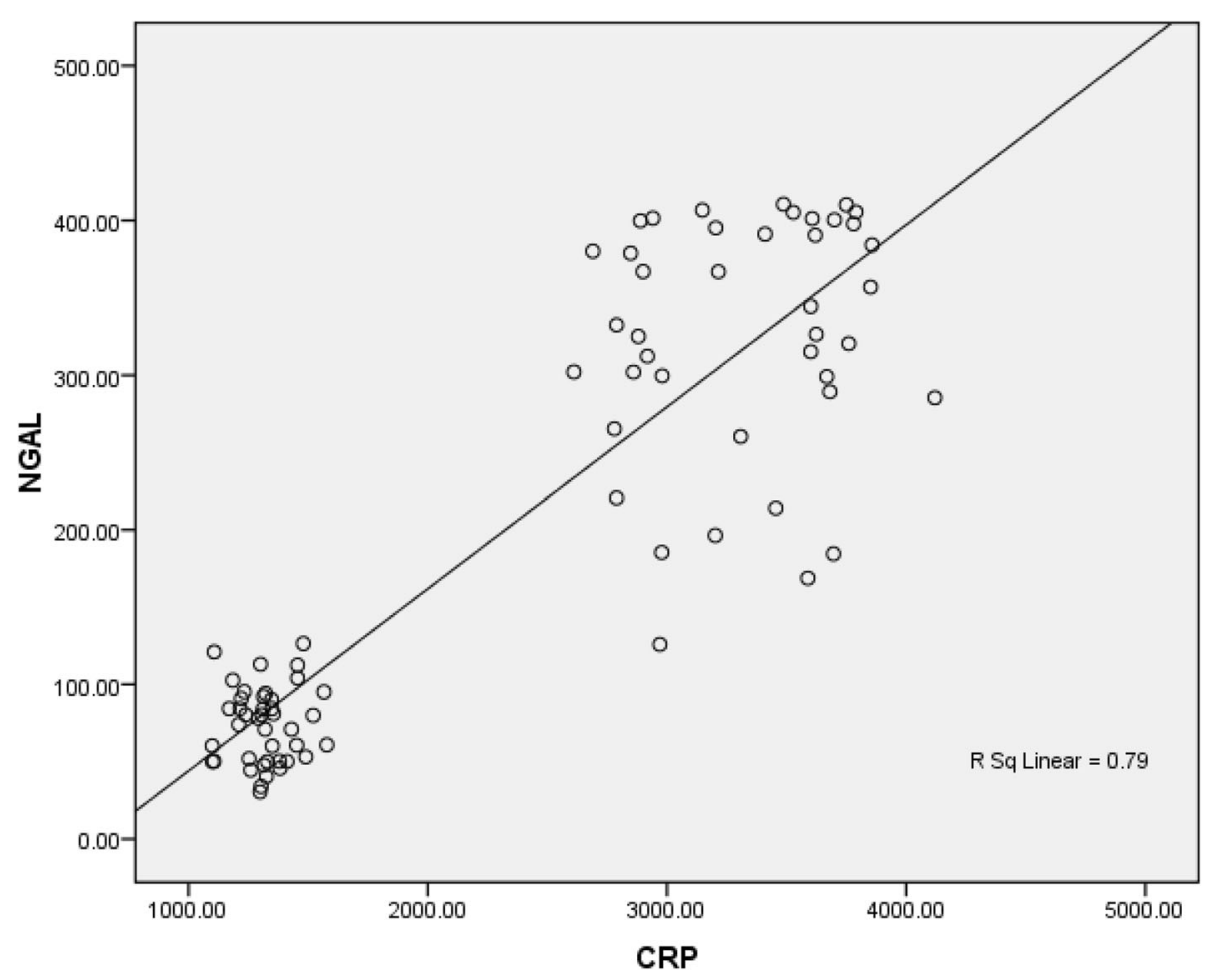

Fig. 4 Scatter diagram showing positive correlation between NGAL and CRP 


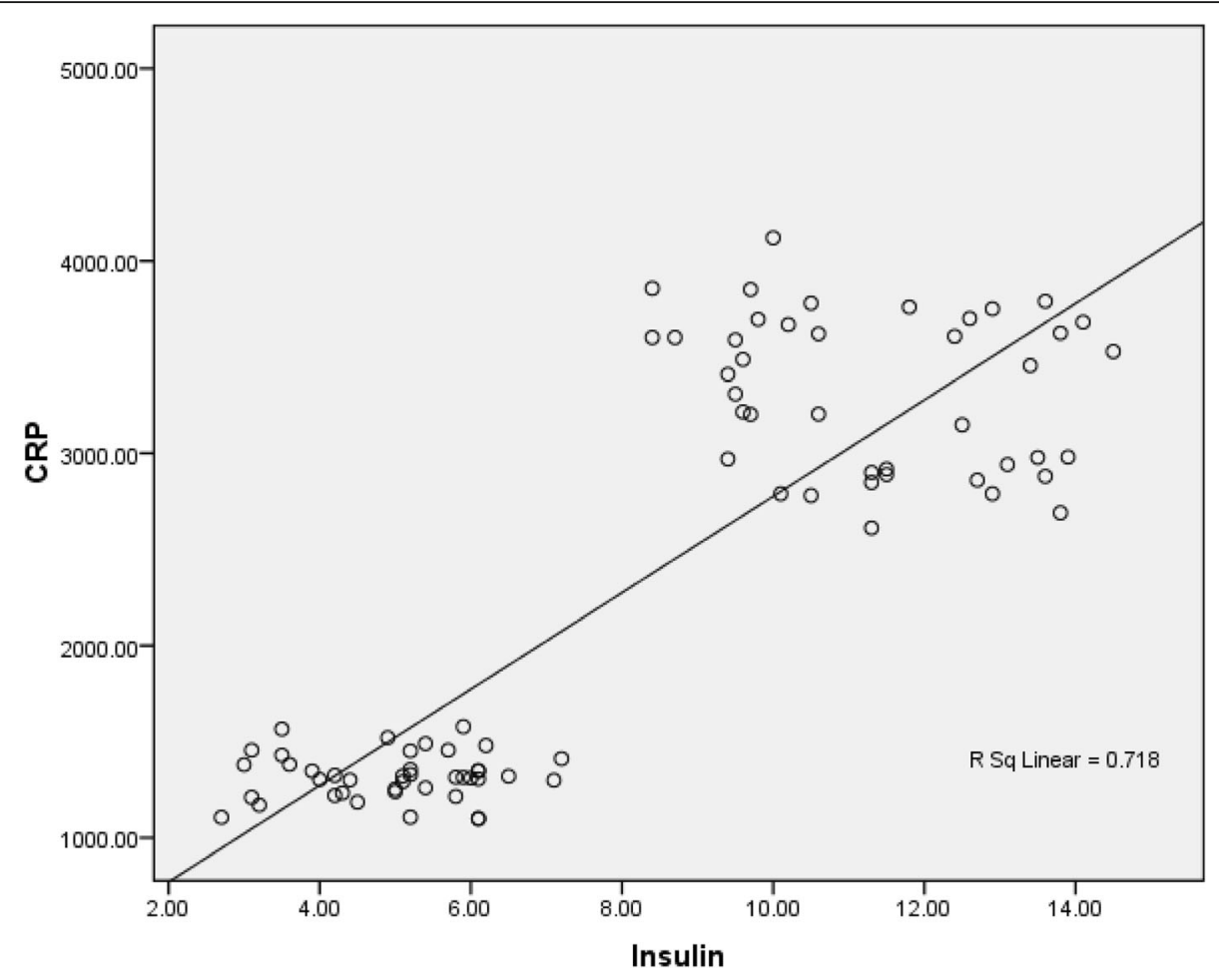

Fig. 5 Scatter diagram showing positive correlation between CRP and insulin

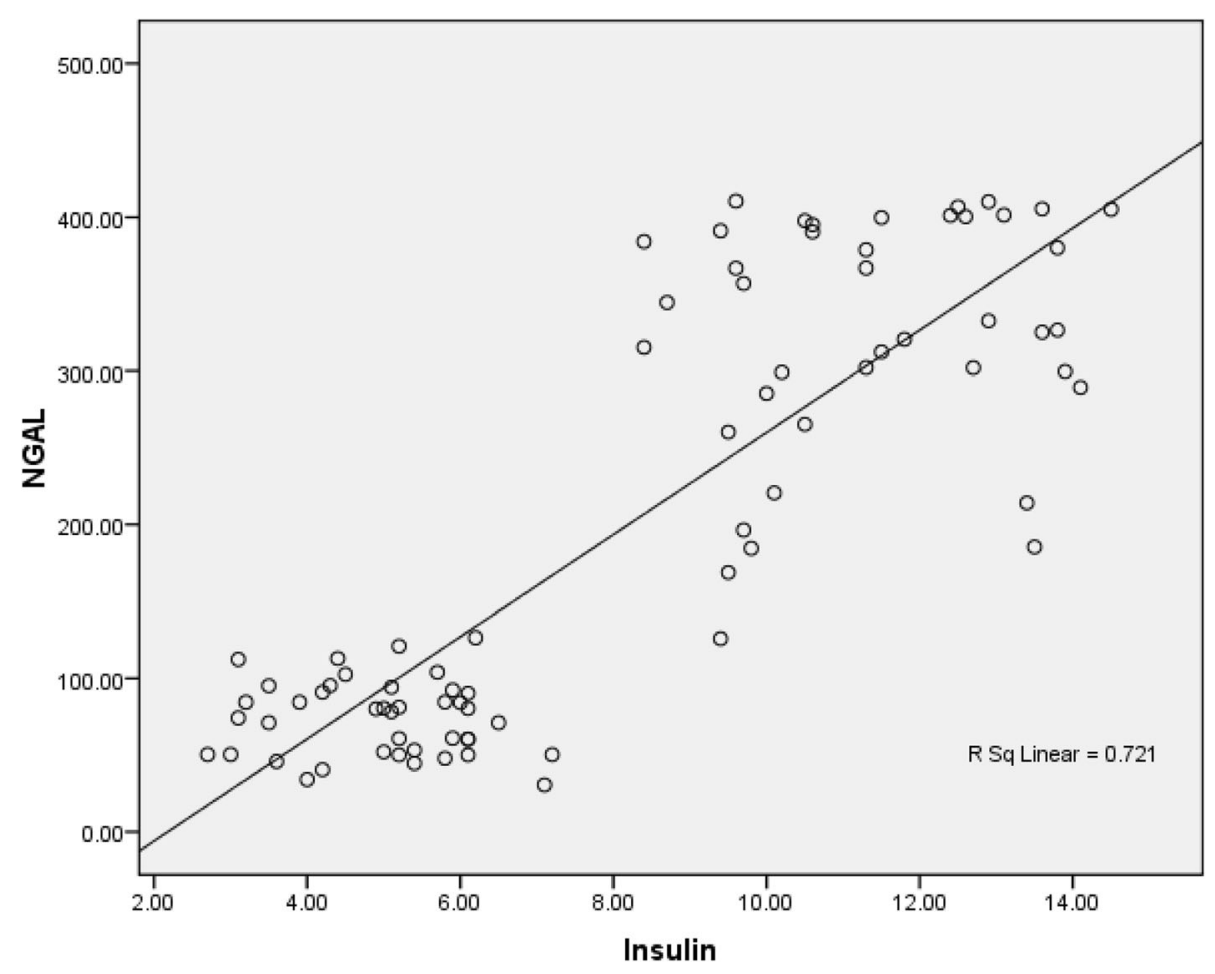

Fig. 6 Scatter diagram showing positive correlation between NGAL and insulin 
Table 3 Comparison of the anthropometric parameters between control and obese groups

\begin{tabular}{lll}
\hline Parameter & Control & Obese \\
\hline BMI $\left(\mathrm{kg} / \mathrm{m}^{2}\right)$ & $19.55 \pm 3.763$ & $38.09 \pm 3.493^{\mathrm{a}}$ \\
Waist circumference $(\mathrm{cm})$ & $71.21 \pm 2.56$ & $106.65 \pm 4.25^{\mathrm{a}}$ \\
Hip circumference $(\mathrm{cm})$ & $89.75 \pm 3.78$ & $123.21 \pm 4.48^{\mathrm{a}}$ \\
Waist-to-hip ratio & $0.7951 \pm 0.062$ & $0.8670 \pm 0.08^{\mathrm{a}}$
\end{tabular}

All data are presented as mean $\pm \mathrm{SE}$

${ }^{\text {a }}$ Significant versus control group at $p<0.05$

immune system. However, on the other side when an overwhelming activation of neutrophils occurs, here liver damage occurs. This "aberrant neutrophil activity" has been evidenced from both human patients and animal investigations as a cause of liver diseases.

In our own words, we can only guess that since NGAL is abundantly expressed in the liver neutrophil granules and has been declared to be implicated in innate immunity, inflammation, and apoptosis (Martins et al. 2014; Zaki et al. 2015); therefore, maybe NGAL too acts as a "double-edged sword". Also, Hafner et al. (2013) suggested that chronic inflammation causes "pre-conditioning" against excessive acute hyper-inflammation.

\section{Conclusions}

NGAL can be used as a biomarker for predicting incidence of NAFLD in obese adolescents.

\section{Abbreviations \\ ALT: Alanine transaminase; AST: Aspartate transaminase; BMI: Body mass index; CRP: C-reactive protein; HDL: High-density lipoprotein; HOMA: Homeostatic Model Assessment; IR: Insulin resistance; LDL: Low- density lipoprotein; NAFLD: Nonalcoholic fatty liver disease; NGAL: Neutrophil gelatinase-associated lipocalin; TNF-a: Tumor necrosis factor-alpha}

\section{Funding}

This work was personally funded by the authors.

\section{Availability of data and materials}

The datasets used and/or analyzed during the current study are available from the corresponding author on reasonable request.

\section{Authors' contributions \\ WA analyzed and interpreted the patients' anthropological data and contributed in writing the manuscript. HAE analyzed and interpreted the patients' biochemical data and contributed in writing the manuscript. OM was a major contributor in writing the manuscript. HAM analyzed and interpreted the patients' biochemical data. GA contributed in analyzing the patients' biochemical data. EM contributed in the laboratory determination and analysis of the patients' biochemical parameters. NA contributed in the interpretation and selection of the suitable cases for the study. MM contributed in the laboratory determination of patients' biochemical parameters. MA contributed in the laboratory determination of patients' biochemical parameters and in writing and editing the manuscript. All authors read and approved the final manuscript.}

\section{Ethics approval and consent to participate}

The study protocol was approved by the Ethical Committee Board of the National Research Centre, Cairo, Egypt, with registration number 17006. An informed written consent was obtained from all participants.

\section{Consent for publication}

Not applicable

\section{Competing interests}

The authors declare that they have no competing interests.

\section{Publisher's Note}

Springer Nature remains neutral with regard to jurisdictional claims in published maps and institutional affiliations.

\section{Author details}

${ }^{1}$ Department of Biological Anthropology, National Research Centre, Cairo 12622, Egypt. ²Department of Medical Biochemistry, National Research Centre, Cairo 12622, Egypt. ${ }^{3}$ Department of Child Health, National Research Centre, Cairo 12622, Egypt. ${ }^{4}$ Department of Clinical Biochemistry, Faculty of Medicine, King Abdulaziz University, Jeddah, Saudi Arabia. ${ }^{5}$ Department of Biochemistry, National Research Centre, Cairo 12622, Egypt. ${ }^{6}$ Department of Pediatrics, Faculty of Medicine, Al-Azhar University, Cairo, Egypt.

Received: 14 June 2018 Accepted: 25 June 2018

Published online: 03 September 2018

\section{References}

Akelma AZ, Abaci A, Ozdemir O, Celik A, Avci Z, Razi CH et al (2012) The association of serum lipocalin-2 levels with metabolic and clinical parameters in obese children: a pilot study. J Pdiatr Endocrinol Metab 525:525-528

Allain CC, Poon LS, Chan CS, Richmond W, Fu PC (1974) Enzymatic determination of total serum cholesterol. Clin Chem 20(4):470-475

Barham D, Trinder P (1972) An improved colour reagent for the determination of blood glucose by the oxidase system. Analyst 97(151):142-145

Basaranoglu M, Basaranoglu G, Bugianesi E (2015) Carbohydrate intake and non alcoholic fatty liver disease: fructose as a weapon of mass destruction. Hepatob Surg Nutr 4(2):109-116

Bergmeyer HU, Horder M, Rej R (1985) Approved recommendation on IFCC methods for the measurement of catalytic concentration of enzymes. J Clin Chem Clin Biochem 24:497-510

Bulluck H, Maiti R, Chakraborty B, Candilio L, Clayton T, Evans R et al. Neutrophil gelatinase-associated lipocalin prior to cardiac surgery predicts acute kidney injury and mortality. Heart 2017; 0:1-5

Chandrasekhar T, Suchitra MM, Sachan A, Bitla AR, Rao PS (2014) Indices of insulin resistance in pediatric obesity. J Clin Sci Res 3:7-13

Dimitrova R, Pelkova V, Dimitrov M, Madzharov V, Nikolova I, Petkova E et al (2014) Obesity relationship with vascular dysfunction. Adv Obes Weight Manag Control 1(1):00001

El-Koofy NM, Anwar GM, El-Raziky MS, El-Hennawy AM, , El-Mougy FM, El-Karaksy $\mathrm{HM}$, et al. The association of metabolic syndrome, insulin resistance, nonalcoholic fatty liver disease in overweight/obese children. Saudi J Gastroenterol 2012; 18(1):44-49

Esser N, Legrand-Poels S, Piette J, Scheen AJ, Paquot N (2014) Inflammation as a link between obesity, metabolic syndrome and type 2 diabetes. Sci Direct 105(2):141-150

Fan JG, Farrell GC (2008) VAT fat is bad for the liver, SAT fat is not. Gastroenterol Hepatol 23:829-832

Fishbein MH, Mogren C, Gleason T, Stevens WR (2006) Relationship of hepatic steatosis to adipose tissue distribution in pediatric non alcoholic fatty liver disease. J Pediatr Gastroenterol Nutr 42(1):83-88

Fried SK, Greenberg AS (2012) Lipocalin 2: a "sexy" adipokine that regulates 17ßestradiol and obesity. Endocrinology 153(4):1582-1584

Friedewald WT, Levy RI, Fredrickson DS (1972) Estimation of the concentration of low density lipoprotein, without use of the preparative ultracentrifugation. Clin Chem 18:499-502

Georgio V, Prono F, Graziano F, Nobili V (2013) Pediatric non alcoholic fatty liver disease: old and new concepts on development, progression, metabolism in sight and potential treatment targets. NMC Pediatrics 13:40

Ghalli I, Salah N, Hussien F, Erfan M, ElRuby M, Mazen I, Sabry M, Abd El-Razik M, Saad M, Hossney L, Ismaail S, Abd El-Dayem S et al (2008) Egyptian growth curves 2002 for infants, children and adolescents. In: Sartorio A, JMH B, Marazzi N (eds) Crescere nel mondo, Ferring Publisher, p 105

Gobato AO, Vasques ACJ, Zambon MP, Filho AB, Hessel G (2014) Metabolic syndrome and insulin resistance in obese adolescents. Rev Paul Pediatr 32(1):55-62

Hafner S, Hillenbrand A, Knippschild U, Radrmacher P (2013) The obesity paradox and acute kidney injury, beneficial effects of hyper inflammation. Crit Care 17(6):1023 
Hiernaux J, Tanner JM (1969) Growth and physical studies. In: Weiner JS, Lourie SA (eds) Human biology: a guide to field methods. Blackwell Scientific Publications, London: IBP; Oxford, UK, pp 315-340

Huang SC, Yang YJ (2013) Serum retinol-binding protein 4 is independently associated with pediatric NAFLD and fasting triglyceride level. J Pediatr Gastroenterol Nutr 56(2):145-150

Lenzi A, Migliaccio S, Donini LM (eds) (2015) Multidisciplinary approach to obesity, 1st edn. Springer International Publishing AG, Basel, p 350

Lichtenauer M, Franz M, Fritzenwanger M, Figulla HR, Gerdes N, Jung C (2015) Elevated plasma levels of interleukin-12 p 40 and interleukin-16 in overweight adolescents. Biomed Res Int 2015:940910

Martins LM, Oliveira ARS, Cruz KJC (2014) Obesity, inflammation and insulin resistance. Braz J Pharm Sci 50(4):677-692

Michael DJ (2008) Role of body fat distribution and the metabolic complications of obesity. J Clin Endocrinol Metab 93:57-63

Mitsnefes M, Kathman T, Mishra J, Kartal J, Khoury P, Nickolas T, Barasch J, Devarajan P (2007) Serum NGAL as a marker of renal function in children with chronic kidney disease. Pediatric Nephrol 22:101-108

Nappo A, lacoviello L, Fraterman A, Gonzalez-Gil EM, Hadjigeorgiou C, Marild S et al (2013) High-sensitivity C-reactive protein is a predictive factor of adiposity in children: results of the identification and prevention of dietary-and lifestyle - induced health effects in children and infants (IDEFICS) study. J Am Heart Assoc 2(3):e000101

Neuschwander-Tetri BA (2017) Non-alcoholic fatty liver disease. BMC Med 15:45-50

Polyzos SA, Kountouras J, Mantzoros CS (2017) Adipose tissue, obesity and nonalcoholic fatty liver disease. Minerva Endocrinol 42:92-108

Puspitadewi A, Sekartini R, Pulungan AB (2013) Prevalence of insulin resistance in obese adolescence. Int J Pediatr Endocrinol 102. https://doi.org/10.1186/ 1687-9856-2013-S1-P102.

Ridker PM, Buring JE, Shih J, Matias M, Hennekens CH (1998) Prospective study of C-reactive protein and the risk of future cardiovascular events among apparently healthy women. Circulation 98(8):731-733

Rodriguez G, Gallego S, Breidenassel C, Moreno LA, Gottrand F (2010) Is liver transaminases assessment an appropriate tool for the screening of nonalcoholic fatty liver disease in at risk obese children and adolescents. Nutr Hosp 25(5):712-717

Schwimmer JB, Zepeda A, Newton KP, Xanthakos SA, Behling C, Hallinan EK et al (2014) Longitudinal assessment of high blood pressure in children with non alcoholic fatty liver disease. PLoS One 9(11):e112569

Seung-Hoi K (2013) Non alcholic fatty liver disease: molecular mechanisms for the hepatic steatosis. CMH 19(3):210-215

Shieh JM, Tsai YJ, Tsou CJ, Wu WB (2014) CXCL1 regulation in human pulmonary epithelial cells by tumor necrosis factor. Cell Physiol Biochem 34:1373-1384

Suarez-Alvarez K, Solis- Lozano L, Leon-Cabrera S, Gonzalez- Chavez A, GómezHernández G, Quiñones-Álvarez MS et al (2013) Serum IL-12 is increased in Mexican obese subjects and associated with low-grade inflammation and obesity-related parameters. Mediat Inflamm 2013:967067

Turkington RW, Estkowkski A, Link M (1982) Secretion of insulin or connecting peptide; a predictor of insulin dependence of obese diabetics. Arch Intern Med 142:1102-1105

Wahlefeld AW (1974) Determination of serum triglycerides level. In: Bergmeyer H (ed) Methods of enzymatic analysis. Academic Press, New York, pp 1831-1835

Wang C (2013) Role of vitamin D in cardiometabolic diseases. J Diabetes Res 2013:243934

Wang Y, Lam KS, Kraeegen EW, Sweeney G, Zhang J, Tso AW et al (2007) Lipocalin-2 is an inflammatory marker closely associate with obesity, insulin resistance and hyperglycemia in humans. Clin Chem 53(1):34-41

Warnick GR, Benderson J, Albers JJ (1982) Dextran sulfate-Mg2+ precipitation procedure for quantification of high-density-lipoprotein cholesterol. Clin Chem 28(6):1379-1388

Wu D, Dawson NAJ, Levings MK (2016) Obesity-associated adipose tissue inflammation and transplantation. Am J Transplant 16:743-750

Xu R, Hung H, Zhang Z, Wang FS (2014) The role of neutrophils in the development of liver disease. Cell Mol Immunol 11(3):224-231

Yan QW, Yang Q, Mody N, Graham TE, Hsu CH, Xu Z et al (2007) The adipokine lipocalin-2 is regulated by obesity and promotes insulin resistance. Diabetes 56:2533-2540

Zaki ME, EL-Bassyouni H, Youness E, Mohamed N (2015) Lipocalin-2 is an inflammatory biomarker associated with metabolic abnormalities in Egyptian obese children. J App Pharm Sci 5(05):007-012

\section{Submit your manuscript to a SpringerOpen ${ }^{\circ}$ journal and benefit from:}

- Convenient online submission

- Rigorous peer review

- Open access: articles freely available online

High visibility within the field

- Retaining the copyright to your article

Submit your next manuscript at $\boldsymbol{\nabla}$ springeropen.com 